\title{
Application of microsatellite markers as potential tools for traceability of Girgentana goat breed dairy products
}

\author{
Maria Teresa Sardina *, Lina Tortorici, Salvatore Mastrangelo, Rosalia Di Gerlando, \\ Marco Tolone, Baldassare Portolano \\ Dipartimento Scienze Agrarie e Forestali, Università degli Studi di Palermo, 90128 Palermo, Italy
}

\section{A R T I C L E I N F O}

\section{Article history:}

Received 23 December 2014

Received in revised form 2 April 2015

Accepted 12 April 2015

Available online 25 April 2015

\section{Keywords:}

Molecular markers

Breed genetic traceability

Girgentana goat dairy products

\begin{abstract}
A B S T R A C T
In livestock, breed assignment may play a key role in the certification of products linked to specific breeds. Traceability of farm animals and authentication of their products can contribute to improve breed profitability and sustainability of animal productions with significant impact on the rural economy of particular geographic areas and on breed and biodiversity conservation. With the goal of developing a breed genetic traceability system for Girgentana dairy products, the aim of this study was to identify specific microsatellite markers able to discriminate among the most important Sicilian dairy goat breeds, in order to detect possible adulteration in Girgentana dairy products. A total of 20 microsatellite markers were analyzed on 338 individual samples from Girgentana, Maltese, and Derivata di Siria goat breeds. Specific microsatellite markers useful for traceability of dairy products were identified. Eight microsatellite markers showed alleles present at the same time in Maltese and Derivata di Siria and absent in Girgentana and, therefore, they were tested on DNA pools of the three breeds. Considering the electropherograms' results, only FCB20, SRCRSP5, and TGLA122 markers were tested on DNA samples extracted from cheeses of Girgentana goat breed. These three microsatellite markers could be applied in a breed genetic traceability system of Girgentana dairy products in order to detect adulteration due to Maltese and Derivata di Siria goat breeds.
\end{abstract}

(c) 2015 Elsevier Ltd. All rights reserved.

\section{Introduction}

In general, traceability can be defined as the ability to follow food through all stages of production, processing and distribution (McKean, 2001). The term "traceability" was defined by the European Regulation (ER) 178/2002 as "the ability to trace and follow a food, fees, food producing animal or ingredients, through all stages of production and distribution". Following the ISO 8402 standards norms, this term was defined as "the capacity of establishing a product's origin process history, use and provenance by reference to written records" (International Organization for Standardization (ISO), 1994). Like other traceability definitions, ISO 8402 did not define which parameters have to be measured or how history or origin should be determined. Traceability systems are mandatory in all European Union member countries and are important for livestock and animal products. There are several types of traceability depending on how it is obtained and on what information it furnished (Dalvit, De Marchi, \& Cassandro, 2007). The conventional traceability consists of the labeling system and of the management of processed food by batches (Schwägele, 2005). Furthermore, it is based on paper documents which could be counterfeited (Cunningham \& Meghen, 2001).

\footnotetext{
* Corresponding author. Tel.: + 39091 23896069; fax: + 3909123860814.

E-mail address: mariateresa.sardina@unipa.it (M.T. Sardina).
}

Genetic traceability is based on the identification of both animal and their products through the study of DNA. DNA molecules have been proposed as target compounds for individual and species identification due to high stability compared with proteins, and also to their presence in most biological tissues, making them the molecules of choice for differentiation and identification of components in food and for the possibility to overcome limits of conventional traceability system (Dalvit et al., 2007; Mafra, Ferreira, \& Oliveira, 2008). In fact, researches have been focused on the study of DNA that is present in every cell and is relatively stable to food processing (Dalvit et al., 2007; Plath, Krause, \& Einspanier, 1997). DNA analysis can furnish a different level of identification. Breed and species discrimination are interesting to detect fraud and to protect and valorize typical productions. First approaches for species identification were based on protein analyses and immunological assay (Berger, Mageau, Schwab, \& Johnston, 1988; Patterson \& Jones, 1990). Nowadays, species-specific PCR has shown to be a reliable method to control the authenticity of dairy products (Galimberti et al., 2013) because a specific target sequence (e.g. 12S rRNA, 16S rRNA, cytochrome $\mathrm{b}$, and cox1 gene suggested as DNA barcode) can be detected in matrices containing a pool of heterogeneous genomic DNA, such as milk (Mafra et al., 2008). Moreover, in recent years, the PCR-denaturing gradient gel electrophoresis (PCR-DGGE) has been used for food traceability and safety in order to characterize bacteria and yeasts in dairy products (Arcuri, El Sheikha, Rychlik, Piro-Métayer, \& Montet, 2013; 
Table 1

Total number of individuals (IDs) used to create the experimental DNA pools using Girgentana (GIR), Maltese (MAL) and Derivata di Siria (DdS) samples. Percentages (\%) of DNA from Girgentana (GIR) and from the two other breeds (MAL + DdS) present within each DNA pool.

\begin{tabular}{lllll}
\hline Total IDs & IDs GIR & IDs MAL + DdS & GIR (\%) & MAL + DdS (\%) \\
\hline 20 & 10 & 10 & 50 & 50 \\
40 & 30 & 10 & 75 & 25 \\
60 & 50 & 10 & 83.3 & 16.7 \\
80 & 70 & 10 & 87.5 & 12.5 \\
100 & 90 & 10 & 90 & 10 \\
\hline
\end{tabular}

Ercolini, Mauriello, Blaiotta, Moschetti, \& Coppola, 2004). Several different markers have been discovered, studied and used in agriculture and livestock; at present, the most widely used for traceability purpose are microsatellites and Single Nucleotide Polymorphisms (SNPs), for their high level of polymorphism and high reproducibility (Galimberti et al., 2013). Microsatellite markers had been widely investigated for many applications such as genetic identification, assessment of parentage, breed assignment tests and traceability (Dalvit et al., 2007; Fernández et al., 2013; Heaton et al., 2002; Orrù, Napolitano, Catillo, \& Moioli, 2006; Rosa, Sardina, Mastrangelo, Tolone, \& Portolano, 2013; Tolone, Mastrangelo, Rosa, \& Portolano, 2012). DNA analysis furnished different levels of identification: individual one is useful for safeguarding public and animal health and providing safe products for both domestic and export consumption (considering also that national disease monitoring depends on correct animal identification), while breed and species discrimination are interesting to detect fraud and to protect and valorize typical products (Bottero \& Dalmasso, 2011; Cunningham \& Meghen, 2001; Dalvit, De Marchi, Targhetta, Gervaso, \& Cassandro, 2008). Breed genetic traceability allowed the assignment or exclusion of the breed of origin to a product. Breed genetic traceability is becoming an important issue for the authentication of their products, as there is an increasing interest in marketing mono-breed labeled lines of meat as well as dairy products, which in some cases have obtained the protected designation of origin (PDO). This interest derives from the fact that a marketing link between breeds and their originated products can contribute to improve breed profitability and sustainability of such farm animal production with significant impact on the rural economy of particular geographic areas and on breed conservation and biodiversity (Russo et al., 2007). Some examples are the Italian PDO cheese Parmigiano Reggiano produced only with milk obtained from the Reggiana dairy cows (Gandini \& Oldenbroek, 1999) and the Spanish PDO Jamon Iberico made with Iberian pig breeds (García et al., 2006). It is important to underline that these products are usually ancient and their preservation is linked with the protection of traditions and cultures. The herds of the utilized breeds are often small and endangered, and their chance of survival is their use for the production of

Table 2

Microsatellite markers panel information.

\begin{tabular}{|c|c|c|c|c|}
\hline Locus name & Primer sequences & Chromosome $^{*}$ & Length range $(\mathrm{bp})^{\dagger}$ & NCBI probe database ${ }^{\ddagger}$ \\
\hline \multirow[t]{2}{*}{ FCB48 } & FW: GACTCTAGAGGATCGCAAAGAACCAG & 17 (Oar) & $145-175$ & 012486890 \\
\hline & RV: GAGTTAGTACAAGGATGACAAGAGGCAC & & & \\
\hline \multirow[t]{2}{*}{ FCB20 } & FW: GGAAAACCCCCATATATACCTATAC & 2 (Oar) & $85-115$ & 012486916 \\
\hline & RV: AAATGTGTTTAAGATTCCATACATGTG & & & \\
\hline \multirow[t]{2}{*}{ BRN } & FW: CCTCCACACAGGCTTCTCTGACTT & 7 (Oar) & $130-165$ & 012487242 \\
\hline & RV: CCTAACTTGCTTGAGTTATTGCCC & & & \\
\hline \multirow[t]{2}{*}{ CSRD247 } & FW: GGACTTGCCAGAACTCTGCAAT & 14 (Oar) & $226-246$ & 012490012 \\
\hline & RV: CACTGTGGTTTGTATTAGTCAGG & & & \\
\hline \multirow[t]{2}{*}{ SRCRSP0005 } & FW: GGACTCTACCAACTGAGCTACAAG & 18 (Oar) & $150-185$ & 012490659 \\
\hline & RV: TGAAATGAAGCTAAAGCAATGC & & & \\
\hline \multirow[t]{2}{*}{ OLADRB } & FW: CTGCCAATGCAGAGACACAAGA & 20 (Oar) & $260-300$ & 012487641 \\
\hline & RV: GTCTGTCTCCTGTCTTGTCATC & & & \\
\hline \multirow[t]{2}{*}{ SRCRSP0008 } & FW: TGCGGTCTGGTTCTGATTTCAC & - & $215-250$ & L22200 \\
\hline & RV: CCTGCATGAGAAAGTCGATGCTTAG & & & \\
\hline \multirow[t]{2}{*}{ INRA104 } & FW: AACATTTCAGCTGATGGTGGC & 20 (Oar) & $135-155$ & 012487361 \\
\hline & RV: TTCTGTTTTGAGTGGTAAGCTG & & & \\
\hline \multirow[t]{2}{*}{ OARAE54 } & FW: TACTAAAGAAACATGAAGCTCCCAC & 25 (Oar) & $110-145$ & 012519055 \\
\hline & RV: GGAAACATTTATTCTTATTCCTCAGTG & & & \\
\hline \multirow{2}{*}{ MB099 } & FW: CTGGAGGTGTGTGAGCCCCATTTA & 1 (Oar) & 178-194 & 012486920 \\
\hline & RV: CTAAGAGTCGAAGGTGTGACTAGG & & & \\
\hline \multirow[t]{2}{*}{ BM1329 } & FW: TTGTTTAGGCAAGTCCAAAGTC & 6 (Oar) & $155-200$ & 012828638 \\
\hline & RV: AACACCGCAGCTTCATCC & & & \\
\hline \multirow[t]{2}{*}{ ETH225 } & FW: GATCACCTTGCCACTATTTCCT & 9 (Oar) & $130-160$ & 012487010 \\
\hline & RV: ACATGACAGCCAGCTGCTACT & & & \\
\hline \multirow[t]{2}{*}{ MCM73 } & FW: CTCTTCATTCTGCAAAAGTTTGTCAC & 4 (Oar) & $105-135$ & 012487638 \\
\hline & RV: GCTTGTGAGATGAACAATAAGTCATAGG & & & \\
\hline \multirow[t]{2}{*}{ FBC11 } & FW: GCAAGCAGGTTCTTTACACTAGCACC & 2 (Oar) & $140-165$ & 012486867 \\
\hline & RV: GGCCTGAACTCACAAGTTGATATATCTATCAC & & & \\
\hline \multirow[t]{2}{*}{ TCRGC4 } & FW: AGAACAAATATCTGGAATGGTGATGCT & 4 (Oar) & $260-320$ & 012518826 \\
\hline & RV: TGCTATAGGATGACATGAAGGCAAAT & & & \\
\hline \multirow[t]{2}{*}{ STAT5B } & FW: TTGGCGGAAATGAGCTGGTGTTTC & 19 (Btau) & $260-320$ & 012490147 \\
\hline & RV: TCCGTCCTGAAGTGATGTTTCCCT & & & \\
\hline \multirow[t]{2}{*}{ INRA023 } & FW: GAGTAGAGCTACAAGATAAACTTC & 3 (Btau) & $180-230$ & 012487309 \\
\hline & RV: TAACTACAGGGTGTTAGATGAACTC & & & \\
\hline \multirow{2}{*}{ SRCRSP0024 } & FW: AGCAAGAAGTGTCCACTGACAG & 2 (Oar) & $140-170$ & 012490656 \\
\hline & RV: TCTAGGTCCATCTGTGTTATTGC & & & \\
\hline \multirow[t]{2}{*}{ TGLA122 } & FW: CCCTCCTCCAGGTAAATCAGC & 18 (Oar) & $125-155$ & 012487076 \\
\hline & RV: AATCACATGGCAAATAAGTACATA & & & \\
\hline \multirow[t]{2}{*}{ MCM64 } & FW: TACAGTCCATGGGGTCACAAGAG & 2 (Oar) & $125-165$ & 012487637 \\
\hline & RV: TCTGAATCTACTCCCTCCTCAGAGC & & & \\
\hline
\end{tabular}

\footnotetext{
* Number of chromosome for Ovis aries (Oar) or Bos taurus (Btau) genome.

+ Minimum and maximum length in base-pairs (bp) for each microsatellite.

* Identification number of each microsatellite marker as reported in National Centre for Biotecnology Information (NCBI) web pages within Probe database (http://www.ncbi.nlm.nih.gov/ probe) and in GenBank database (www.ncbi.nlm.nih.gov/genbank/).
} 
Table 3

Number of alleles (k), observed (Ho) and expected (He) heterozygosity, polymorphic information content (PIC), and summary statistics for the 19 polymorphic microsatellite markers.

\begin{tabular}{lllll}
\hline Locus & $\mathrm{k}$ & Ho & He & PIC \\
\hline FCB48 & 8 & 0.777 & 0.793 & 0.763 \\
FCB20 & 9 & 0.754 & 0.783 & 0.749 \\
BRN & 12 & 0.735 & 0.860 & 0.844 \\
CSRD247 & 7 & 0.884 & 0.719 & 0.674 \\
SRCRSP05 & 11 & 0.728 & 0.766 & 0.731 \\
OLADRB & 11 & 0.732 & 0.822 & 0.799 \\
SRCRSP08 & 9 & 0.540 & 0.603 & 0.536 \\
INRA104 & 3 & 0.430 & 0.459 & 0.369 \\
OARAE54 & 9 & 0.467 & 0.565 & 0.540 \\
MB099 & 5 & 0.214 & 0.297 & 0.264 \\
MCM73 & 7 & 0.524 & 0.624 & 0.582 \\
FCB11 & 8 & 0.563 & 0.827 & 0.802 \\
BM1329 & 10 & 0.674 & 0.674 & 0.642 \\
ETH225 & 3 & 0.148 & 0.161 & 0.153 \\
INRA023 & 8 & 0.624 & 0.687 & 0.631 \\
SRCRSP24 & 11 & 0.518 & 0.596 & 0.566 \\
TCRGC4 & 6 & 0.705 & 0.706 & 0.653 \\
TGLA122 & 11 & 0.485 & 0.535 & 0.504 \\
MCM64 & 11 & 0.556 & 0.810 & 0.788 \\
Mean \pm S.D. & $8.368 \pm$ & $0.582 \pm$ & $0.647 \pm$ & $0.610 \pm$ \\
Number of loci & 2.692 & 0.187 & 0.185 & 0.188 \\
Total number of alleles & 19 & & & \\
Total number of individuals & 159 & & & \\
Mean proportion of & 338 & & & \\
individuals typed & 0.963 & & & \\
\hline
\end{tabular}

typical and high quality products. This means that breed traceability is important both to defend and valorize particular food products and livestock breeds.

An interesting situation is represented by the Girgentana goat (Capra hircus), an ancient breed reared in a restricted area of Sicily (southern Italy) for its good dairy production. Due to sanitary policies, the size of the Girgentana population decreased almost $90 \%$ in 20 years. In 1983, the population consisted of 30,000 goats but nowadays only 374 heads are enrolled in the Herd Book (Associazione Nazionale della Pastorizia, Asso.Na.Pa., 2013) and it was listed by Food and Agriculture Organization (FAO) with endangered risk status. Over recent years this breed has become almost extinct, in part as a consequence of marked decrease in fresh goat milk consumption. Therefore, it could be interesting to evaluate the possibility of revitalizing interest in milk produced by this breed in order to regain an important economic role in the production of drinking milk (such as milk for infants) and niche dairy products (Mastrangelo, Sardina, Tolone, \& Portolano, 2013). Recently, emerging interests in this breed have resulted in the production of typical dairy products obtained with only Girgentana milk.

With the goal of developing a genetic traceability system for dairy products, the aim of this study was to identify specific microsatellite markers able to discriminate among the most important Sicilian dairy goat breeds, in order to detect possible adulteration in Girgentana dairy products. For this purpose we have focused our attention mainly on the three most important local goat breeds reared in Sicily, Girgentana, Maltese and Derivata di Siria.

\section{Materials and methods}

\subsection{Blood sampling and DNA extraction}

For this preliminary study, a total of 338 individual samples, belonging to Girgentana (264), Maltese (41) and Derivata di Siria (33) goat breeds were collected during March 2013. Animals were randomly sampled from different flocks located in Sicily provinces (Global Positioning System coordinates reported in Table S1). About $10 \mathrm{ml}$ of blood was collected from jugular vein using Vacutainer tubes containing Ethylenediaminetetraacetic acid (EDTA) as anticoagulant. Genomic DNA was extracted from buffy coats of nucleated cells using a salting out method (Miller, Dykes, \& Polesky, 1988). The concentration of extracted DNA was checked using NanoDrop ND-1000 spectrophotometer (NanoDrop Technologies, Wilmington, DE, USA) and samples were stored at $4{ }^{\circ} \mathrm{C}$ until use.

\subsection{Cheese sampling and DNA extraction}

A total of three cheese samples of Girgentana goat breed were collected from Sicilian local dairy farms and stored at $-20{ }^{\circ} \mathrm{C}$ until use. Farmers declared that milk from other goat breeds was not used to produce these cheeses. As the milk contains somatic cells that are included as component in cheese and in other processed dairy products, the DNA from these cells represents the trace of the milk producer animals. For DNA extraction the Cetyl trimethylammonium bromide (CTAB) method of ISO 21571:2005 (E) (International Organization for Standardization (ISO), 2005) was used, making some changes to the protocol for sample preparation ( $5 \mathrm{~g}$ of cheese sample, use of proteinase $\mathrm{K}$, and incubation overnight at $50{ }^{\circ} \mathrm{C}$ ). Three samples from each cheese were collected for DNA extraction and used as technical and biological replicates. The concentration of extracted DNA was checked using NanoDrop ND-1000 spectrophotometer (NanoDrop Technologies, Wilmington, DE, USA) and samples were stored at $4{ }^{\circ} \mathrm{C}$ until use.

Table 4

Private alleles (frequencies in brackets) found in the three goat breeds: Girgentana (GIR), Maltese (MAL), and Derivata di Siria (DdS). Alleles in bold and underlined could be used for traceability purpose for their presence in MAL and DdS and, at the same time, their absence in GIR.

\begin{tabular}{|c|c|c|c|}
\hline \multirow[t]{2}{*}{ Locus } & \multicolumn{3}{|l|}{ Breed } \\
\hline & GIR & MAL & DdS \\
\hline FCB48 & $154(0.0284)$ & $156(0.0854)$ & $156(0.1250)$ \\
\hline \multirow[t]{3}{*}{ FCB20 } & & $\overline{93(0.0488)}$ & \\
\hline & & $105(0.0122)$ & \\
\hline & & $109(0.0122)$ & $109(0.0303)$ \\
\hline \multirow[t]{3}{*}{ BRN } & $156(0.1060)$ & $\overline{166(0.0128)}$ & \\
\hline & $158(0.0682)$ & & \\
\hline & $160(0.0076)$ & & \\
\hline CSRD247 & & $246(0.2927)$ & \\
\hline \multirow[t]{3}{*}{ SRCRSP05 } & $159(0.0076)$ & $177(0.2195)$ & $177(0.1364)$ \\
\hline & & $\overline{181(0.0732)}$ & \\
\hline & & $183(0.0732)$ & \\
\hline \multirow[t]{2}{*}{ OLADRB } & $269(0.0377)$ & $291(0.0122)$ & $291(0.0156)$ \\
\hline & $293(0.0139)$ & & \\
\hline \multirow[t]{4}{*}{ SRCRSP08 } & & $228(0.0610)$ & \\
\hline & & $230(0.0366)$ & $230(0.0606)$ \\
\hline & & & $\overline{236(0.0152)}$ \\
\hline & & & $240(0.0152)$ \\
\hline OARAE54 & $130(0.0511)$ & $128(0.0244)$ & \\
\hline \multirow[t]{2}{*}{ MB099 } & & $157(0.0122)$ & \\
\hline & & $187(0.0244)$ & $187(0.0781)$ \\
\hline \multirow[t]{2}{*}{ MCM73 } & $122(0.0153)$ & & \\
\hline & $132(0.0118)$ & & \\
\hline \multirow[t]{2}{*}{ FCB11 } & & $155(0.1625)$ & \\
\hline & & $161(0.0125)$ & \\
\hline BM1329 & & $163(0.0139)$ & \\
\hline \multirow[t]{2}{*}{ ETH225 } & & $145(0.2073)$ & $145(0.0152)$ \\
\hline & $149(0.0760)$ & & \\
\hline \multirow[t]{2}{*}{ SRCRSP24 } & $144(0.0019)$ & $150(0.0854)$ & $162(0.0156)$ \\
\hline & & & $168(0.0156)$ \\
\hline TCRGC4 & & & $173(0.0152)$ \\
\hline \multirow[t]{5}{*}{ TGLA122 } & $133(0.0153)$ & $139(0.0385)$ & \\
\hline & $145(0.0019)$ & & \\
\hline & $147(0.0210)$ & & \\
\hline & & $151(0.0769)$ & $151(0.0606)$ \\
\hline & & $\overline{197(0.0128)}$ & \\
\hline \multirow[t]{2}{*}{ MCM64 } & $149(0.0344)$ & $137(0.0122)$ & \\
\hline & $151(0.0496)$ & & \\
\hline
\end{tabular}




\subsection{Experimental DNA pools preparation}

Several DNA pools were prepared mixing DNA from Girgentana, Maltese and Derivata di Siria goat breeds in different proportion (Table 1). The DNA pools were created considering the different alleles present in the three goat breeds in order to assess the detection power of microsatellite markers.

\subsection{Microsatellite markers amplification and analysis}

A total of 20 microsatellite markers were amplified in five multiplexPCR reactions (Table 2). Markers were chosen according to the International Society for Animal Genetics (ISAG)/Food and Agricultural Organization (FAO) (2004) or obtained from the NCBI website (www. ncbi.nlm.nih.gov/probe, www.ncbi.nlm.nih.gov/genbank/), in order to be polymorphic and located all over the genome. Each PCR reaction was performed in a total volume of $10 \mu \mathrm{l}$ containing $100 \mathrm{ng}$ of genomic DNA, 1X PCR buffer with $\left(\mathrm{NH}_{4}\right)_{2} \mathrm{SO}_{4}, 2.5 \mathrm{mM} \mathrm{MgCl} 2,0.8 \mathrm{mM}$ dNTPs, primer mix and $1 \mathrm{U}$ of Taq DNA polymerase. The thermal cycling condition were initial denaturation at $95{ }^{\circ} \mathrm{C}$ for $10 \mathrm{~min}, 35$ cycles $95{ }^{\circ} \mathrm{C}$ for $1 \mathrm{~min}, 56^{\circ} \mathrm{C}$ for $1 \mathrm{~min}$, and $72{ }^{\circ} \mathrm{C}$ for $2 \mathrm{~min}$, followed by final extension at $60{ }^{\circ} \mathrm{C}$ for $30 \mathrm{~min}$. Capillary electrophoresis was performed using ABI PRISM 3130xl Genetic Analyzer (Applied Biosystems, Foster City, CA) and GeneScan LIZ500 (Applied Biosystems, Foster City, CA) as internal size standard. Allele size was assigned using GeneMapper v4.0 software (Applied Biosystems, Foster City, CA).

Microsatellite markers with alleles present at the same time in Maltese and Derivata di Siria breeds and absent in Girgentana breed were tested on DNA pools prepared with different proportion of the three breeds (Table 1) and on DNA samples from Girgentana cheeses.

To evaluate data repeatability and reproducibility, a total of 5 samples per breed were genotyped in duplicate and analyses were carried out independently by two experienced operators. The differences between the raw values obtained for each allele were directly analyzed with GeneMapper v4.0 software (Applied Biosystems, Foster City, CA) and compared with GeneScan LIZ500 in order to estimate the uniformity and stability of each allele of each microsatellite.

\subsection{Statistical analysis}

Allele frequencies, mean number of alleles (MNA), allelic richness (AR), observed (Ho) and expected (He) heterozygosity, Polymorphic Information Content (PIC), and exact P-value associated with the null hypothesis of Hardy Weinberg equilibrium (HWE) for all loci were estimated using CERVUS 3.0.3 (Marshall, Slate, Kruuk, \& Pemberton, 1998), FSTAT 2.9.3.2 (Goudet, 1995), ARLEQUIN 3.5.1.2 (Excoffier \& Lischer, 2010), and GENEPOP 4.0.11 (Rousset, 2008) software.

\section{Results and discussion}

\subsection{Microsatellite markers panel results}

All 338 individual samples belonging to Girgentana (264), Maltese (41), and Derivata di Siria (33) goat breeds were genotyped for 20 microsatellite markers. Of the 20 microsatellite markers used in this study, STA5B was monomorphic in all breeds and, therefore, it was excluded from the statistical analyses. In Table 3, the number of detected alleles, Ho and He, and PIC for the 19 analyzed loci are shown. A total of 159 alleles have been identified in the Sicilian goat breeds. Observed number of alleles per locus ranged from 3 (INRA104 and ETH225) to 12 (BRN). Considering that PIC value was higher than 0.50, the microsatellite panel was highly informative (Botstein, White, Skolnick, \& Davis, 1980). The microsatellite set gave satisfactory results in all breeds in terms of reproducibility and repeatability and this simplified the
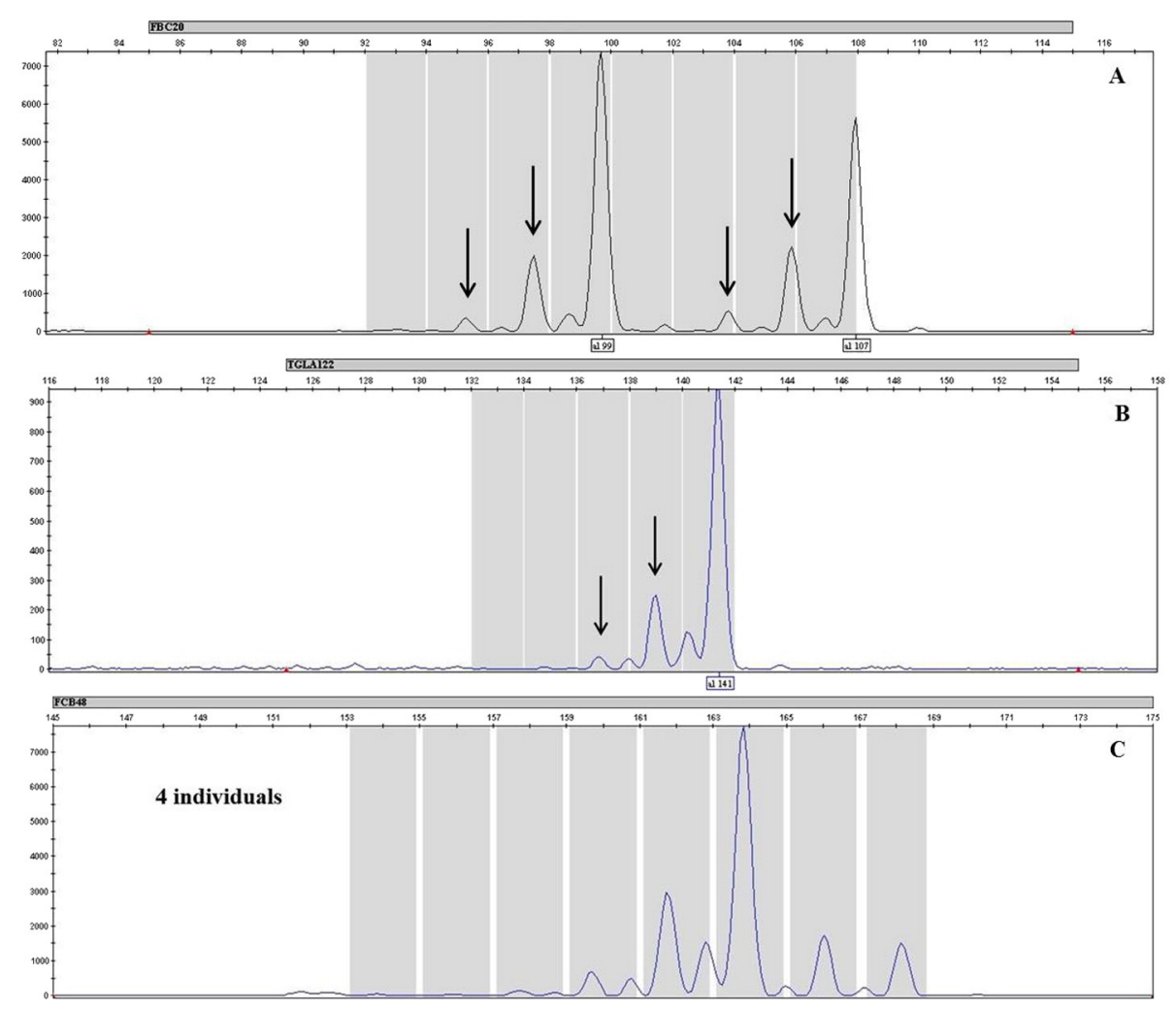

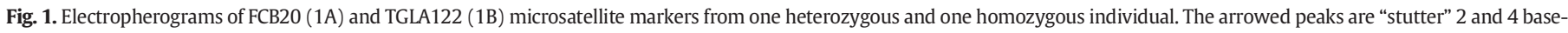

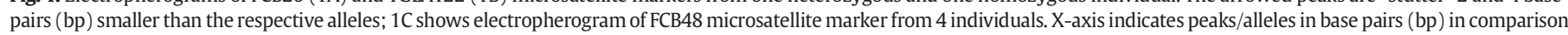
with GeneScan LIZ500 Size standard; all peaks are scaled in relative fluorescent unit (r.f.u.) on Y-axis. 

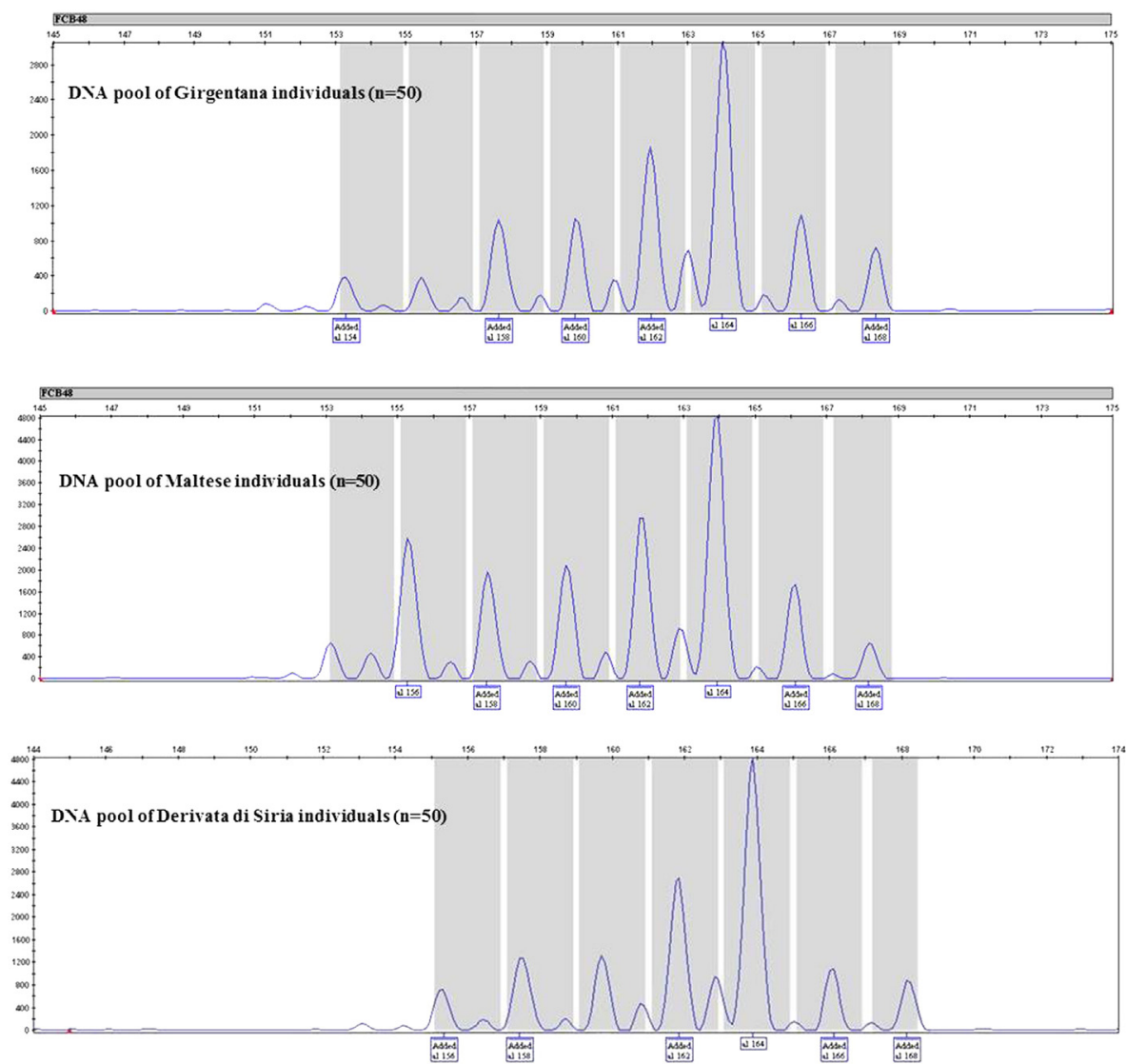

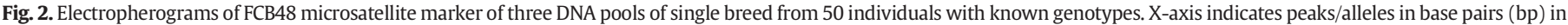
comparison with GeneScan LIZ500 Size standard; all peaks are scaled in relative fluorescent unit (r.f.u.) on Y-axis.

laboratory work and reduced the analyses costs. Moreover, the mean proportion of individuals typed was 0.96 and this set showed good variability considering the mean values of $\mathrm{Ho}$ and $\mathrm{He}$ ( 0.53 and 0.65 , respectively). Only two microsatellite markers (CSRD247 and FCB11) were not in HWE in Girgentana, Maltese and Derivata di Siria goat breeds (data not shown).

\subsection{Identification of breed specific microsatellite markers}

Nowadays, several molecular tools can be applied to assess authenticity and adulteration of dairy products (Galimberti et al., 2013). These methods allowed the identification of species-specific target sequences within matrices (e.g. 12S rRNA, 16S rRNA, cytochrome b, and cox1 gene) and can be only used to perform species genetic traceability (Galimberti et al., 2013). To achieve the aim of this study, our first step was to identify breed specific microsatellite markers that can be used for breed genetic traceability of Girgentana dairy products. Presence of private alleles (i.e. alleles present in one breed and absent in the others) was evidenced in each breed. In particular, 17 private alleles were found in Girgentana, 16 in Maltese, and 5 in Derivata di Siria goat breeds (Table 4). Considering the allele distribution within the three breeds, it is possible to note some differences that can be used to identify or exclude the breed of origin of dairy product. For this purpose, we have focused our attention mainly on the alleles present at the same time in Maltese and Derivata di Siria and absent in Girgentana. In fact, the deterministic approach is based on the identification and use of few breed specific or exclusive markers present or absent in all animals of a particular breed, and that can be applied to mixture of products obtained from more animals.

Only eight microsatellite markers showed these alleles as reported in Table 4, therefore they were tested on DNA pools of Girgentana, Maltese and Derivata di Siria breeds and subsequently on DNA samples extracted from cheeses.

When microsatellite markers are analyzed, small amounts of fragments smaller/greater than the "real" allele are also amplified. This phenomenon is routinely referred to as "stutter" and, when present, it could

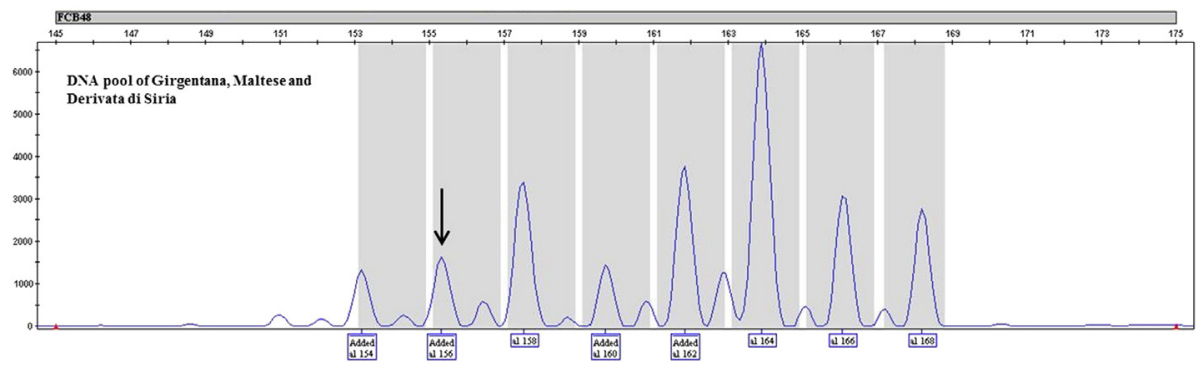

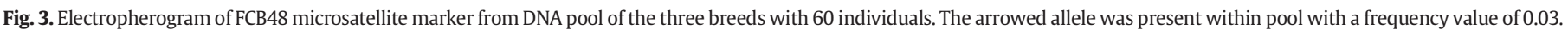
$\mathrm{X}$-axis indicates peaks/alleles in base pairs (bp) in comparison with GeneScan LIZ500 Size standard; all peaks are scaled in relative fluorescent unit (r.f.u.) on Y-axis. 

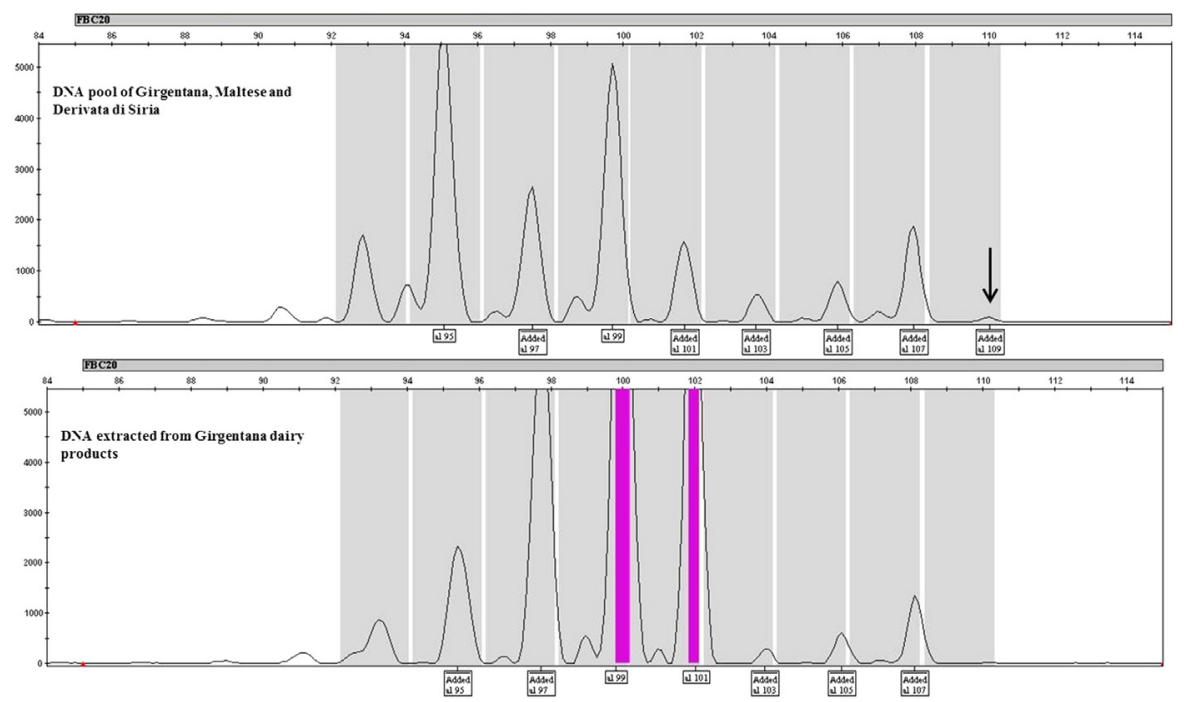

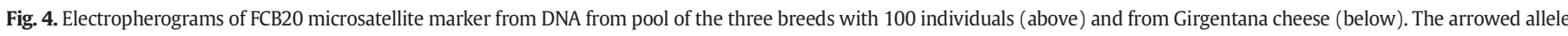

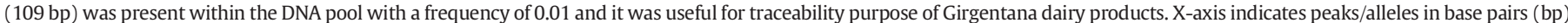

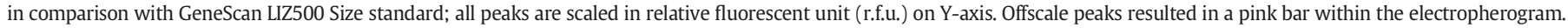

be difficult to distinguish low peaks due to "stutter" from their interaction with true alleles (Shackell, Mathias, Cave, \& Dodds, 2005). The analyzed microsatellite markers presented real allele peaks and "stutter" 2 and/or 4 base-pairs smaller and/or greater than the respective alleles (Fig. 1A). When analysis is performed on single individuals, it was easy to distinguish between alleles and "stutter" even if the analyzed samples were heterozygous (Fig. 1B). Otherwise, when DNA pools contained mixture of DNA from different individuals, the electropherograms showed peaks that are combination of true alleles and the "stutter" from these alleles (Fig. 1C). Therefore, depending on the shape of microsatellite it could be difficult to distinguish between low peaks due to "stutter" and alleles of individuals making a minor contribution to the pool. Considering that DNA pools were constructed with genotyped individuals of the three goat breeds, we could know all the real alleles present within electropherograms and therefore we assigned alleles to any of the observed peaks. To test the eight microsatellites, we first analyzed each of them on DNA pools of single breed made by mixing an increasing number of individuals (from 2 to 50) with known genotypes. In Fig. 2 we reported, as example, the FCB48 microsatellite marker analyzed on 3 DNA pools containing 50 individuals each and we could observe good amplification results. Subsequently, we performed the same analyses on five different DNA pools (Table 1) made mixing DNA from the three breeds with the same good results. In particular, as reported in Fig. 3, allele 156 bp presents with low frequency (0.03) within Maltese and Derivata di Siria was successfully detected.

After visual inspection of microsatellite markers by GeneMapper v4.0 software, it was possible to detect that only three markers, i.e.

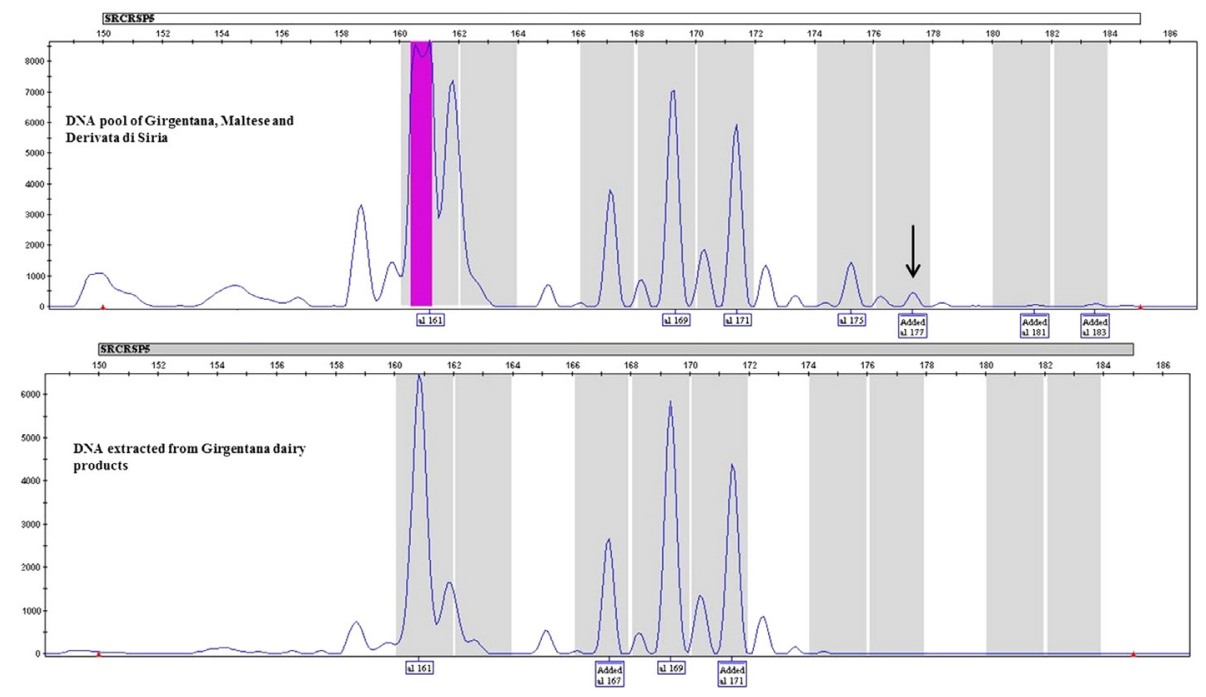

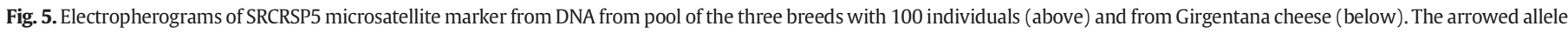

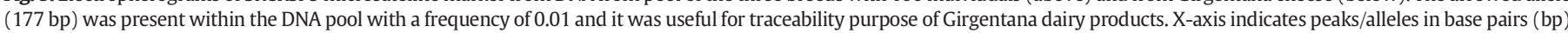

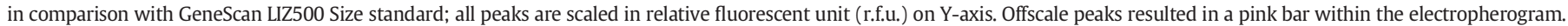



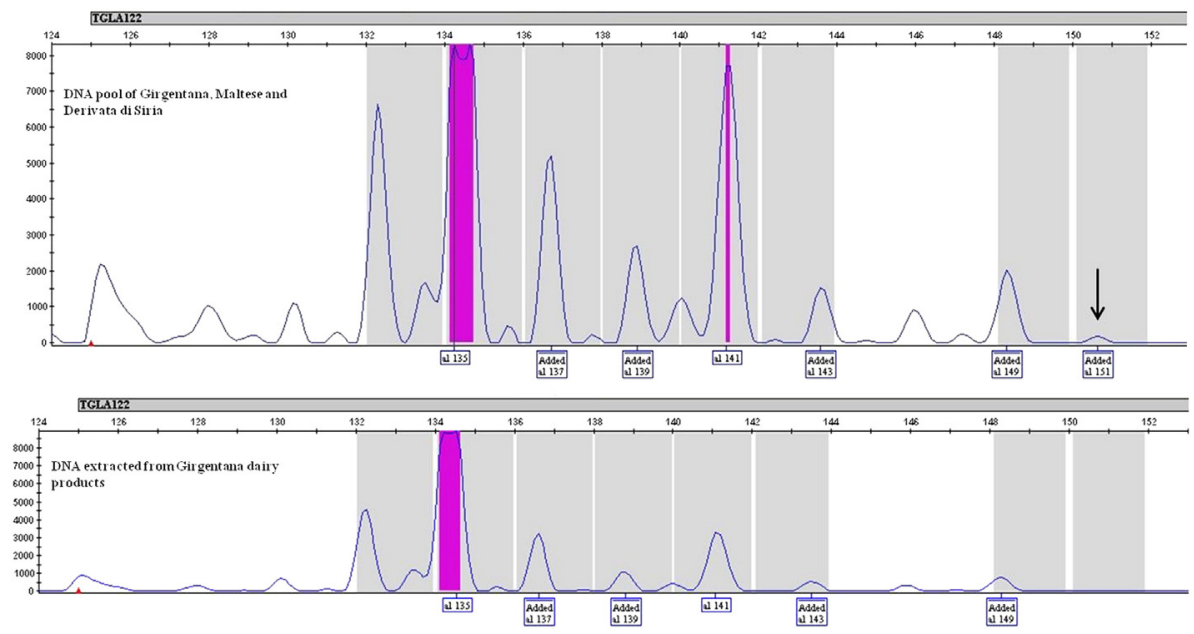

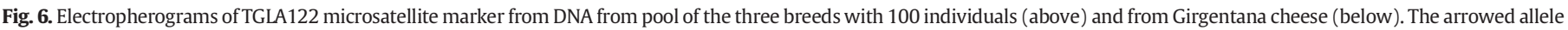

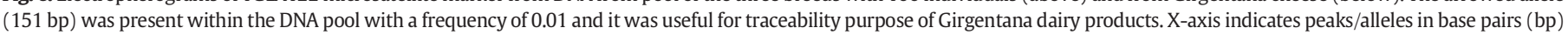
in comparison with GeneScan LIZ500 Size standard; all peaks are scaled in relative fluorescent unit (r.f.u.) on Y-axis. Offscale peaks resulted in a pink bar within the electropherogram.

FCB20, SRCRSP5, and TGLA122, presented alleles useful for traceability purpose of Girgentana dairy products. In fact, these three markers presented the same smallest or greatest allele in Maltese and Derivata di Siria breeds and, therefore, it was possible to detect the real allele peaks even when the analyzed sample containing not genotyped individuals.

\subsection{Application of specific microsatellite markers to cheese DNA samples}

We analyzed FCB20, SRCRSP5, and TGLA122 markers in DNA samples extracted from cheeses $(n=3)$ and we repeated the analysis on replicates ( 9 samples in total). Moreover, we compared the electropherograms with those obtained from DNA pool with 9:1 ratio (Table 1) and we did not detect specific alleles of Maltese and Derivata di Siria breeds (Figs. 4, 5, and 6). Considering our results, these microsatellite markers could be applied in a genetic traceability system of Girgentana dairy products in order to detect adulteration due to Maltese and Derivata di Siria goat breeds. Concerning other goat breeds reared in Sicily (Argentata dell'Etna, Messinese, Saanen and Camosciata delle Alpi), it should be improbable that the Girgentana products are obtained with mixtures of milk from these breeds, especially because they are not reared in the same geographical area of Girgentana goat.

We obtained very good amplifications of DNA from cheese and replicates showed high reliability. Shackell et al. (2005) using microsatellite markers for traceability of ground beef mixtures showed that their PCR reactions were generally repeatable with low variability. Nevertheless, the method was not accurate enough when they analyzed samples consisting of more than 10 individual contributors. Several authors (Dalvit et al., 2008; Fernández et al., 2013; Heaton et al., 2014) reported the use of microsatellite markers and SNPs as potential tool for meat individual traceability and breed traceability on single meat cut. To the best of our knowledge, this work was the first to extend the potential use of microsatellite markers for traceability purpose on dairy products. In fact, nowadays, useful markers for this purpose were identified by looking at mutations in genes determining the most important traits that differentiate the breeds, as the coat color (Fontanesi et al., 2011; Russo et al., 2007). Moreover, our results confirmed the absence of adulteration in the analyzed Girgentana dairy products and suggested that it could be possible to identify "foreign" alleles even if they are present with low frequency.

One relevant aspect when studying this topic is the knowledge of population structure and genetic relationship for the breeds involved in the traceability system (Dalvit et al., 2008). The positive results obtained in this were also due to the genetic separation of Girgentana, from the other goat breeds for the differences in breeding system and origin (Siwek, Finocchiaro, Curik, \& Portolano, 2010).

The results can represent a first deterrent against fraud and an important tool for the valorization of Girgentana breed and for authentication of cheese obtained from Girgentana milk only.

\section{Conclusion}

Conventional traceability system based on paper documents could be counterfeited while genetic traceability is based on the identification of both animal and their products through the study of DNA and therefore is more reliable. The possibility of certifying origin and identity of dairy products, through breed characterization, could provide the development of marginal areas in which these products are made, as well as the conservation of Sicilian local breeds. The present study reported for the first time the potential application of microsatellite markers in a breed genetic traceability system for dairy products. Considering our results, FCB20, SRCRSP5, and TGLA122 microsatellite markers will be applied in a breed genetic traceability system of Girgentana dairy products in order to detect adulteration due to Maltese and Derivata di Siria goat breeds, and can represent a first deterrent against fraud and an important tool for the valorization of Girgentana breed. In order to confirm the results further analyses will be conducted using these microsatellite markers on a wider sample of breeds.

Supplementary data to this article can be found online at http://dx. doi.org/10.1016/j.foodres.2015.04.038.

\section{Authors' contributions}

MTS, SM and BP conceived and designed the experiments. MTS and SM drafted the manuscript. RDG, LT and MT carried out DNA extraction and analyses. MTS and SM analyzed the data and performed the statistical analysis. All authors contributed to editing of the article and approved the final manuscript.

\section{Acknowledgments}

This work was supported by Rural Development Program, PSR 2007-2013, Misura 1.2.4, by Sicilia Region, Italy, Grant N. CUPG66D11000039999. 


\section{References}

Arcuri, E.F., El Sheikha, A.F. Rychlik, T., Piro-Métayer, I., \& Montet, D. (2013). Determination of cheese origin by using $16 \mathrm{~S}$ rDNA fingerprinting of bacteria communities by PCRDGGE: Preliminary application to traditional Minas cheese. Food Control, 30, 1-6.

Associazione Nazionale della Pastorizia, Asso.Na.Pa. (2013). Available from http://www. assonapa.it/norme_ecc/Consistenze_Caprini.htm

Berger, R., Mageau, K., Schwab, B., \& Johnston, R. (1988). Detection of poultry and pork in cooked and canned meat foods by enzyme-linked immunosorbent assays. Journal of Association of Official Analytical Chemists, 71, 406-409.

Botstein, D., White, R.L., Skolnick, M., \& Davis, R.W. (1980). Construction of a genetic linkage map in man using restriction fragment length polymorphism. The American Journal of Human Genetics, 32, 324-331.

Bottero, M.T., \& Dalmasso, A. (2011). Animal species identification in food products: Evolution of biomolecular methods. The Veterinary Journal, 1902, 34-38.

Cunningham, E.P., \& Meghen, C.M. (2001). Biological identification systems: Genetic markers. Revue scientifique et technique (International Office of Epizootics), 20(2), 491-499.

Dalvit, C., De Marchi, M., \& Cassandro, M. (2007). Genetic traceability of livestock products: A review. Meat Science, 77, 437-449.

Dalvit, C., De Marchi, M., Targhetta, C., Gervaso, M., \& Cassandro, M. (2008). Genetic traceability of meat using microsatellite markers. Food Research International, 41, 301-307.

Ercolini, D., Mauriello, G., Blaiotta, G., Moschetti, G., \& Coppola, S. (2004). PCR-DGGE fingerprints of microbial succession during a manufacture of traditional water buffalo mozzarella cheese. Journal of Applied Microbiology, 96, 263-270.

European Commission (2002). Council Regulation (EC) No 178/2002 of 28 January 2002 laying down the general principles and requirements of food law, establishing the European Food Safety Authority and laying down procedures in matters of food safety. Official Journal of the European Communities, L 31, 1-24.

Excoffier, L., \& Lischer, H.E.L. (2010). Arlequin suite ver 3.5: A new series of programs to perform population genetics analyses under Linux and Windows. Molecular Ecology Resources, 10, 564-567.

Fernández, M.E., Goszczynski, D.E., Lirón, J.P., Villegas-Castagnasso, E.E., Carino, M.H., Ripoli, M.V., et al. (2013). Comparison of the effectiveness of microsatellites and SNP panels for genetic identification, traceability and assessment of parentage in an inbred Angus herd. Genetics and Molecular Biology, 36, 185-191.

Fontanesi, L., Beretti, F., Dall'Olio, S., Portolano, B., Matassino, D., \& Russo, V. (2011). A melacortin 1 receptor (MC1R) gene polymorphism is useful for authentication of massese sheep dairy products. Journal of Dairy Research, 78, 122-128.

Galimberti, A., De Mattia, F., Losa, A., Bruni, I., Federici, S., Casiraghi, M., et al. (2013). DNA barcoding as a new tool for food traceability. Food Research International, 50, 55-63.

Gandini, G.C., \& Oldenbroek, J.K. (1999). Choosing the conservation strategy. In J.K. Oldenbroek (Ed.), Genebanks and conservation of farm animal genetic resources (pp. 11-31). Lelystad, The Netherlands: DLO Institute for Animal Science and Health.

García, D., Martínez, A., Dunner, S., Vega-Pla, J.L., Fernández, C., Delgado, J.V., et al. (2006). Estimation of the genetic admixture composition of Iberian dry-cured ham samples using DNA multilocus genotypes. Meat Science, 72, 560-566.

Goudet, J. (1995). FSTAT (version1.2), a computer program to calculate F-statistics. Journal of Heredity, 8, 485-486.

Heaton, M.P., Harhay, G.P., Bennett, G.L., Stone, R.T., Grosse, W.M., Casas, E., et al. (2002). Selection and use of SNP markers for animal identification and paternity analysis in U.S. beef cattle. Mammalian Genome, 13, 272-281.
Heaton, M.P., Leymaster, K.A., Kalbfleisch, T.S., Kijas, J.W., Clarke, S.M., McEwan, J., et al (2014). SNPs for parentage testing and traceability in globally diverse breeds of sheep. PLoS ONE, 9, e94851.

International Organization for Standardization (ISO) (1994). ISO 8402: Quality management and quality assurance-Vocabulary. Geneva: ISO.

International Organization for Standardization (ISO) (2005). ISO 21571 Foodstuffs-Methods of analysis for the detection of genetically modified organisms and derived products-Nucleic acid extraction (1st ed.). Geneva: ISO (43 pp.).

International Society for Animal Genetics (ISAG)/Food and Agricultural Organization (FAO) (2004). Secondary guidelines for development of national farm animal genetic resources management plans. Measurement of Domestic Animal Diversity (MoDAD): Recommended Microsatellite Markers.

Mafra, I., Ferreira, I.M.P.V.O., \& Oliveira, M.B.P.P.O. (2008). Food authentication by PCRbased methods. European Food Research and Technology, 227, 649-665.

Marshall, T.C., Slate, J., Kruuk, L.E.B., \& Pemberton, J.M. (1998). Statistical confidence for likelihood-based paternity influence in natural populations. Molecular Ecology, 7. 639-655.

Mastrangelo, S., Sardina, M.T., Tolone, M., \& Portolano, B. (2013). Genetic polymorphism at the CSN1S1 gene in Girgentana dairy goat breed. Animal Production Science, 53, 403-406.

McKean, J.D. (2001). The importance of traceability for public health and consumer protection. Reveu scientifique et technique (International Office of Epizootics), 20, 363-378.

Miller, S.A., Dykes, D.D., \& Polesky, H.F. (1988). A simple salting out procedure for extracting DNA from human nucleated cells. Nucleic Acids Research, 16, 1215.

Orrù, L., Napolitano, F., Catillo, G., \& Moioli, B. (2006). Meat molecular traceability: How to choose the best set of microsatellites? Meat Science, 72, 312-317.

Patterson, R.L.S., \& Jones, S.J. (1990). Review of current techniques for the verification of the species origin of meat. Analyst, 115, 501-506.

Plath, A., Krause, I., \& Einspanier, R. (1997). Species identification in dairy products by three different DNA-based techniques. Zeitschrift für Lebensmittel Untersuchung und Forschung, 205, 437-441.

Rosa, A.J.M., Sardina, M.T., Mastrangelo, S., Tolone, M., \& Portolano, B. (2013). Parentage verification of Valle del Belice dairy sheep using multiplex microsatellite panel. Small Ruminant Research, 113, 62-65.

Rousset, F. (2008). Genepop'007: A complete re-implementation of the Genepop software for Windows and Linux. Molecular Ecology Resources, 8, 103-106.

Russo, V., Fontanesi, L., Scotti, E., Tazzoli, M., Dall'Olio, S., \& Davoli, R. (2007). Analysis of melanocortin 1 receptor (MC1R) gene polymorphisms in some cattle breeds: their usefulness and application for breed traceability and authentication of Parmigiano Reggiano cheese. Italian Journal of Animal Science, 6, 257-272.

Schwägele, F. (2005). Traceability from a European perspective. Meat Science, 71, 164-173.

Shackell, G.H., Mathias, H.C., Cave, V.M., \& Dodds, K.G. (2005). Evaluation of microsatellites as a potential tool for product tracing of ground beef mixture. Meat Science, 70, 337-345.

Siwek, M., Finocchiaro, R., Curik, I., \& Portolano, B. (2010). Hierarchical structure of the Sicilian goats revealed by Bayesian analyses of microsatellite information. Animal Genetics, 4, 93-95.

Tolone, M., Mastrangelo, S., Rosa, A.J.M., \& Portolano, B. (2012). Genetic diversity and population structure of Sicilian sheep breeds using microsatellite markers. Smal Ruminant Research, 102, 18-25. 